\title{
Bir Tıp Fakültesi Hastanesinde Çalışan Hasta Bakıcıların Kas İskelet Sistemi Sağlığının Değerlendirilmesi
}

\section{Evaluation of Patient Caregivers' Musculoskeletal System Health That Working in a Medical Faculty Hospital}

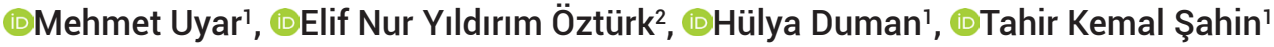 \\ ${ }^{1}$ Necmettin Erbakan Üniversitesi Meram Tıp Fakültesi, Halk Sağlığı Anabilim Dalı, Türkiye \\ ${ }^{2}$ Konya Akşehir İlçe Sağlık Müdürlügüu, Konya, Türkiye
}

Copyright @ 2020 by authors and Medical Records Publishing Inc.

\begin{abstract}
$\mathrm{Oz}$
Amaç: Bu çalışmada bir tıp fakültesi hastanesinde çalışmakta olan hasta bakıcıların kas-iskelet sistemi sağlığının değerlendirilmesi ve kas-iskelet sağlığı ile ilişkili olabilecek faktörlerin belirlenmesi amaçlanmıştır.

Materyal ve Metod: Araştırma kesitsel türdedir. Araştırmanın yapılabilmesi için etik kurul izni alınmıştır. Araştırma kapsamına toplam 302 hasta bakıcıdan çalışmaya katılmayı kabul eden 260'ı alınmıştır. Veri toplama formu olarak 17 soruluk anket, Nordic kas iskelet

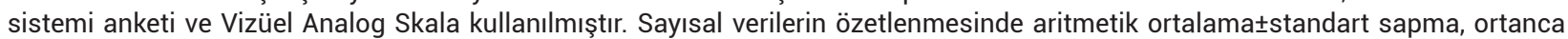
(minimum-maksimum) değerleri kullanılmıştır. Sayısal veriler arasındaki ilişkiler bağımsız gruplarda t testi ve tek yönlü varyans analizi ile değerlendirilmiştir. İstatistiksel olarak $p<0,05$ olan durumlar anlamlı kabul edilmiştir.

Bulgular. Hasta bakıcıların yaş ortalaması 36,76 $\pm 7,37$ idi. Hasta bakıcıların \%42,3'ü ( $n=107)$ kas-iskelet siteminde işe başladıkları tarihten itibaren ortaya çıkan ağrı şikayeti bulunduğunu belirtti. Kas-iskelet sisteminde ağrı şikâyeti bulunan katılımcıların ağrı skoru ortalaması 4,69 $\pm 2,20$ idi. Nordic kas iskelet sistemi anketine göre son 12 ay içerisinde hasta bakıcıların \%24,7'si $(n=64)$ alt sırt ağrısı ve \%24,2'si ( $n=62)$ omuz ağrısı yaşamıştı. Ağrı şiddetinde cinsiyet, çalışma durumu ve eğitim durumu açısından istatistiksel olarak anlamlı farklılık bulundu $(\mathrm{p}<0,05)$.

Sonuç: Hasta bakıcıların yaklaşık yarısının kas-iskelet sisteminde ağıı bulunmaktadır. Son bir yıl içerisinde en sık alt sırt, omuz ve üst sırt ağrısı yaşanmıştır. Yaklaşık \%80 hasta bakıcının hafif ve orta şiddette ağrısı vardır.
\end{abstract}

Anahtar Kelimeler. Hasta bakıcı, işe bağlı kas iskelet sistemi hastalığı, Nordic kas iskelet sistemi anketi, vizüel analog skala

\begin{abstract}
Aim: In this study, it was aimed to evaluate the health of the musculoskeletal system of the caregivers working in a medical faculty hospital and to determine the factors related to musculoskeletal health.

Material and Methods: The research is cross-sectional. Ethics committee approval is obtained for conducting the study. A total of 302 patients who agreed to participate in the study are included in the study. Data is collected using a 17-item questionnaire, Nordic musculoskeletal questionnaire and Visual Analogue Scale. Arithmetic mean \pm standard deviation, median (minimum-maximum) values are used to summarize numerical data. The relationships between numerical data are evaluated by independent samples $t$ test and one way ANOVA. Statistically, $\mathrm{p}<0.05$ is considered significant.

Results: The mean age of the caregivers was $36.76 \pm 7.37$ years. $42.3 \%(n=107)$ of the caregivers stated that they had pain in the musculoskeletal system since the date they started working. The mean pain score was $4.69 \pm 2.20$. According to the Nordic musculoskeletal questionnaire, $24.7 \%(n=64)$ of the caregivers experienced lower back pain and $24.2 \%(n=62)$ of shoulder pain in the last 12 months. Pain severity was found to be statistically different in terms of gender, working status and education level ( $p<0.05$ ). Conclusion: About half of the caregivers have pain in the musculoskeletal system. In the last year, the most common pain is lower back, shoulder and upper back. Approximately $80 \%$ of the caregivers have mild to moderate pain.
\end{abstract}

Keywords: Caregiver, work related musculoskeletal disease, Nordic musculoskeletal questionnaire, visual analogue scale

Geliş Tarihi / Received: 13.05.2020 Kabul Tarihi / Accepted: 10.06.2020

Sorumlu Yazar /Corresponding Author. Elif Nur Yıldırım Öztürk, Konya Akşehir İlçe Sağlık Müdürlüğü, Akşehir, Konya, Türkiye E-mail: elifnyildirim@hotmail.com Phone: +90 05549610370 


\section{GiRiş}

Bütün iş yerlerinde, çalışan sağlığını ve güvenliğini tehdit eden işle ilgili faktörler bulunmaktadır (1). Başta hastaneler olmak üzere sağlık kurumları, çalışanlarda sağlık sorunlarına yol açabilecek çok çeşitli ortam faktörlerini çalışma ortamında barındırmaktadır (2). Çalışma ortamı ile çalışanların sağlığı arasında iki yönlü bir etkileşim vardır. Çalışma koşulları çalışanın sağlığını etkilerken; sağlık da bireyin çalışma kapasitesini etkilemektedir (3).

İşe bağlı hastalıklar içerisinde en sık izlenen grup kas-iskelet sistemi hastalıklarıdır. İşe bağlı hastalık yeni olgularının \%50'sini işe bağlı kas-iskelet sistemi hastalıkları (iKiH) meydana getirmektedir (4). Hekim, diş hekimi, fızyoterapist, hemşire ve hasta bakıcılar yaptıkları iş sebebiyle kas-iskelet sistemini ilgilendiren sağlık sorunlarına sürekli olarak maruz kalmaktadırlar (5).

IKIH en sık tek veya tekrarlayan travma nedeniyle kas, ligaman, tendon, sinir, kemik ve eklemleri etkileyen inflamatuvar ve dejeneratif durumları içermektedir $(6,7)$. IKIH fiziksel, sosyal, kültürel ve kişisel risk faktörleri ile yakından ilişkilidir (8). Eğilme, itme ve çekme hareketleri, durağan çalışma pozisyonu, ağırlık kaldırma, tekrarlayan hareketler, vibrasyon, uzun süreli, ağır ve yoğun çalışma gibi fiziksel risk faktörleri kas-iskelet sistemi ağrıları ile sonuçlanabilmektedir (9). İKiH ayrıca işe gelmeme, istirahat izni ve erken emeklilik gibi nedenlerle üretkenliği azaltarak toplumda ekonomik etkilere neden olmaktadır (6).

Bu çalışmada bir tıp fakültesi hastanesinde çalışmakta olan hasta bakıcıların kas-iskelet sistemi sağlığının değerlendirilmesi ve kas-iskelet sağlığı ile ilişkili olabilecek faktörlerin belirlenmesi amaçlanmıştır.

\section{MATERYAL VE METOD}

Araştırma kesitsel türde tasarlanmış epidemiyolojik bir çalışmadır. Araştırmanın yapılabilmesi için Necmettin Erbakan Üniversitesi Meram Tıp Fakültesi İlaç ve Tıbbi Cihaz Dışı Etik Kurulu'ndan izin alınmıştır (Sayı: 2019/1935, Tarih: 21.06.2019). Araştırma Helsinki Deklarasyonu, 2013'e uygun olacak şekilde yürütülmüştür.

Araştırmanın evrenini Konya ili Meram ilçesinde bulunan Necmettin Erbakan Üniversitesi Meram Tıp Fakültesi Hastanesi'nde görev yapmakta olan hasta bakıcılar oluşturmuştur. Çalışma için örneklem büyüklüğü hesaplanmamış olup evrenin tamamına (302 kişi) ulaşılması hedeflenmiştir. Araştırma 01.07.201901.09.2019 tarihleri arasında çalışmaya katılmak için yazılı ve sözlü onam veren kadın ve erkek 260 hasta bakıcı üzerinde yapılmıştır. Evrenin \%86'sına ulaşılmıştır.

Araştırma için literatür taramasının ardından toplam 17 sorudan ve 2 temel bölümden oluşan bir veri toplama formu geliştirilmiştir. Formun 9 sorudan oluşan ilk bölümü katılımcıların sosyodemografık özelliklerini ve 8 sorudan oluşan ikinci bölümü hasta bakıcıların bazı sağlık özelliklerini sorgulamaktadır. Veri toplama formunda ayrıca Vizüel Analog Skala (VAS) ve Nordic Kas İskelet
Sistemi Anketi (NKISA) yer almaktadır. VAS günlük pratikte ağrı değerlendirmesi için oldukça yaygın kullanılan bir skaladır. Ölçüm aracı Albersnagel tarafından geliştirilmiş olup (10), kültürel uyarlaması Aydın ve arkadaşları (11) tarafından yapılmıştır. VAS'ta $10 \mathrm{~cm}$ 'lik bir ölçek üzerinde 0 ile 10 arasında değişen ağrı ortalamaları verilmektedir. Buna göre " 0 " ağıının olmadığını belirtirken ortalama VAS değerinin "1-4" olması hafif ağrı, "5-6" olması orta şiddette ağrı, "7-10" olması şiddetli ağrıyı ifade etmektedir $(12,13)$. VAS, katılımcılara 0'dan 10'a kadar her rakamın bir çizgiyle işaretlendiği toplam $10 \mathrm{~cm}$ 'lik bir ölçek olarak sunulmuş ve katılımcılardan ağrı düzeylerini bu ölçek üzerinde işaretlemeleri istenmiştir. Tam sayılar haricinde işaretleme yapan katılımcıların ağrı düzeyleri cetvelle ölçülerek kaydedilmiştir. NKISA boyun, omuz, sırt, dirsek, el/el bileği, bel, kalça/uyluk, diz, ayak/ayak bileği olmak üzere dokuz bölgeyi anatomik olarak gösteren bir şekil üzerinde ağrının olup olmadığını sorgulayan bir ankettir. Form çalışanlar üzerinde ve/veya genel toplumda yapılan çalışmalarda dokuz vücut bölgesinde son 12 ay içinde ve son 7 gün içinde acı, ağrı veya rahatsızlık olup olmadığı ile son 12 ay içinde kas-iskelet sistemi rahatsızlığı nedeniyle işten kalma durumunu evet/hayır şeklinde sorgulamaktadır (14). Veri toplama formları ve ölçekler gönüllü katılımcılara gözlem altında uygulama metoduyla uygulanmış olup her bir form ortalama 20 dakikada doldurulmuştur.

\section{İstatistiksel Analiz}

Veri girişi, istatistiksel analiz ve rapor yazım işlemleri bilgisayar ortamında gerçekleştirilmiştir. Analizler için SPSS for Windows version 15.0(SPSS Inc., Chicago, IL, USA) yazılımı kullanılmıştır. Sayısal verilerin özetlenmesinde aritmetik ortalama, standart sapma, ortanca, minimum, maksimum değerleri; kategorik verilerin özetlenmesinde frekans dağılımları ve yüzdelikler kullanılmıştır. Sayısal veriler arasındaki ilişkiler dağılımın normal olduğu durumlarda bağımsız gruplarda t testi ve tek yönlü varyans analizi ile değerlendirilmiştir. Dağılımın normal olmadığı durumlarda, aynı testlerin non-parametrik karşılıklarının kullanılması kararlaştırılmıştır. İstatistiksel olarak p'nin 0,05'ten küçük olduğu durumlar anlamlı kabul edilmiştir.

\section{BULGULAR}

\section{Hasta Bakıcıların Sosyodemografik Özellikleri}

Çalışma kapsamında bulunan 260 kişinin yaş ortalaması $36,76 \pm 7,37$; yaş ortancası $37(20-59)$ idi. Katılımcıların şu anki işlerinde ortalama çalışma süresi $9,65 \pm 6,35$; ortanca çalışma süresi 9 (1-31) yıl idi. Hasta bakıcılara ilişkin sosyodemografik özellikler Tablo 1 'de sunulmuştur.

\section{Hasta Bakıcıların Kas-İskelet Sistemi ile illişkili Özellikleri}

Hasta bakıcıların \%42,3'ü $(n=107)$ kas-iskelet siteminde işe başladıkları tarihten itibaren ortaya çıkan ağrı şikâyeti bulunduğunu belirtti. Kas-iskelet sistemi ile ilişkili olan servikal disk hernisi, lumbal disk hernisi, menisküs gibi bir hastalık tanısı olanların oranı \%22,2 $(n=57)$ idi. Katılımcıların bazı özellikleri Tablo 2'de sunulmuştur.

Kas-İskelet sisteminde ağrı şikâyeti bulunan katılımcıların 
VAS ile ağrı skoru ortalaması 4,69 $\pm 2,20$ ve ortancası 5 (1$10)$ idi. Katılımcıların $\% 44,7$ 'sinin $(n=46)$ hafif ağrısı ( $1-4$ puan), \%35'inin ( $n=36$ ) orta şiddette ağrısı (5-6 puan) ve $\% 20,4$ 'ünün $(n=21)$ şiddetli ağrısı (7-10 puan) mevcuttu.

NKISA'ya göre son 12 ay içerisinde hasta bakıcıların $\% 24,7$ 'si $(n=64)$ alt sırt ağrısı ve \%24,2'si $(n=62)$ omuz ağrısı yaşamıştı. Katılımcıların NKISA sonuçları Tablo 3'te sunulmuştur.

Son 7 gün içerisinde hasta bakıcıların \%6,6'sı $(n=17)$ alt sırt, \%6,3'ü ( $n=16)$ üst sırt ve \%5'i $(n=13)$ omuz bölgesinde acı/ağrı/rahatsızlık/uyuşma gibi bir semptom hissetmişti. Son 12 ay içerisinde hasta bakıcıların \%7,8'i $(n=20)$ alt sırt, $\% 5,9^{\prime} u(n=15)$ boyun ve \%5,8'i $(n=15)$ diz nedeniyle işten kalmıştı.

\section{Özellikler}

Yaş (yıl)

Ort $\pm S S$

$36,76 \pm 7,37$

Ortanca (Min-Max)

37 (20-59)

Kadın

$19,6(51)$

Cinsiyet [\% (n)]

Erkek

80,4 (209)

Toplam

$100,0(260)$

Evli

$81,1(210)$

Bekar

13,1 (34)

Medeni Durum [\% (n)]

Eğitim Durumu [\% (n)]

Çalışma Durumu [\% (n)]

Çalışma Sistemi [\% (n)]

Çalıştığı Bölüm [\% (n)]

Boşanmış/Dul

Toplam

$5,7(15)$

100,0 (259)

ilköğretim

$68,8(181)$

Ortaöğretim

$22,7(59)$

Lisans

$7,7(20)$

Toplam

$100,0(260)$

Kadrolu

$8,1(21)$

Özel Firma

91,9 (238)

Toplam

100,0 (259)

Sürekli gündüz mesaisi

33,1 (86)

$7,3(19)$

$59,6(155)$

$100,0(260)$

$56,2(146)$

43,8 (114)

$100,0(260)$

26,8 (67)

73,2 (183)

$100,0(250)$

$16,34 \pm 8,50$

16 (1-48)

$9,65 \pm 6,35$

9 (1-31)

Ortanca (Min-Max)

$9,50 \pm 6,09$

Ort_SS

$9(1-33)$ 
Özellikler

Kas-İskelet Sisteminde Ağrı Şikâyeti

Bulunma Durumu

Kas-İskelet Sistemi İle ilgili Hastalık Tanısı

Bulunma Durumu

Ağrı Kesici Kullanma Durumu

Son 1 Yıl İçinde Fiziksel Tıp ve

Rehabilitasyon Polikliniğine Başvurma

Durumu

\section{Ağrı Kesici Kullanan Hasta Bakıcıların} Kullanma Sıklığı

\section{Son 1 Yıl İçinde Ortopedi Polikliniğine Başvurma Durumu}

Son 1 Yıl İçerisinde Kas-İskelet Sistemi Hastalığı Nedeniyle İstirahat Raporu Alma

\section{Bir Sağlık Sorunu Nedeniyle İş Değiştirme} Durumu

\begin{tabular}{|c|c|}
\hline Var & $42,3(107)$ \\
\hline Yok & $57,7(146)$ \\
\hline Toplam & $100,0(253)$ \\
\hline Var & $22,2(57)$ \\
\hline Yok & $77,8(200)$ \\
\hline Toplam & $100,0(257)$ \\
\hline Kullanıyor & 73,5 (191) \\
\hline Kullanmıyor & $26,5(69)$ \\
\hline Toplam & $100,0(260)$ \\
\hline Arada sırada kullanıyor & $93,7(177)$ \\
\hline Düzenli olarak kullanıyor & $6,3(12)$ \\
\hline Toplam & $100,0(189)$ \\
\hline Başvuranlar & $10,0(26)$ \\
\hline Başvurmayanlar & $90,0(234)$ \\
\hline Toplam & $100,0(260)$ \\
\hline Başvuranlar & $19,2(50)$ \\
\hline Başvurmayanlar & $80,8(210)$ \\
\hline Toplam & $100,0(260)$ \\
\hline Alanlar & $7,8(20)$ \\
\hline Almayanlar & $92,2(237)$ \\
\hline Toplam & $100,0(257)$ \\
\hline Değiştirenler & $2,3(6)$ \\
\hline Değiştirmeyenler & $97,7(254)$ \\
\hline Toplam & $100,0(260)$ \\
\hline
\end{tabular}


Tablo 3. Hasta Bakıcıların Son 12 Ay İ̧inde Kas-iskelet Sistemi Semptomu Yaşama Durumları

İlgili bölgede* acı/ağrı/rahatsızlık/uyuşma hissetme durumu;

Hayır

Boyun*

\begin{tabular}{l} 
Omuzlar* \\
Dirsekler* \\
\hline
\end{tabular}

Bilekler/Eller*

Üst Sırt*

Alt Sirt*

Bir ya da her iki kalça/uyluk*

Bir ya da her iki diz*

Bir ya da her iki ayak bileği/ayak*
Evet

Toplam

Hayır

Evet, sağ omzumda

Evet, sol omzumda

Evet, her iki omzumda

Toplam

Hayır

Evet, sağ dirseğimde

Evet, sol dirseğimde

Evet, her iki dirseğimde

Toplam

Hayır

Evet, sağ bileğimde/sağ elimde

Evet, sol bileğimde/sol elimde

Evet, her iki bileğimde/elimde

Toplam

Hayır

Evet

Toplam

Hayır

Evet

Toplam

Hayır

Evet

Toplam

Hayır

Evet

Toplam

Hayır

Evet

Toplam
$\%$ (n)

79,2 (205)

20,8 (54)

100,0 (259)

75,8 (197)

12,7 (33)

1,9 (5)

9,6 (25)

$100,0(260)$

90,3 (234)

5,4 (14)

1,5 (4)

$2,7(7)$

100,0 (259)

86,9 (226)

6,2 (16)

$2,7(7)$

4,2 (11)

$100,0(260)$

78,6 (202)

21,4 (55)

100,0 (257)

$75,3(195)$

24,7 (64)

100,0 (259)

$86,9(225)$

13,1 (34)

100,0 (259)

78,8 (204)

21,2 (55)

100,0 (259)

96,1 (246)

$3,9(10)$

$100,0(256)$ 
Özellikler

Cinsiyet*

Tanı konulmuş kas-iskelet sistemi hastalığı*

Çalışma durumu*

Son 1 yıl içinde FTR polikliniğine başvurma durumu*

Son 1 yıl içinde ortopedi polikliniğine başvurma durumu*

Son 1 yıl içinde kas-iskelet rahatsızlığına bağlı istirahat raporu alma durumu*

Sağlık sorunu nedeniyle iş değiştirme durumu*

Eğitim durumu**
Ort $\pm S S$

$3,73 \pm 3,18$

$$
\text { Kadın*** }
$$

Erkek

$\operatorname{Var} * * *$

Yok

Kadrolu***

Şirket Personeli

Başvurmuş***

Başvurmamış

Başvurmuş̧**

Başvurmamış

Almış***

Almamış

Değiştirmiş***

Değiştirmemiş

Ortaokul

Lise

Üniversite***

$1,51 \pm 2,40$

$4,53 \pm 2,99$

$1,19 \pm 2,09$

$4,05 \pm 2,61$

$1,76 \pm 2,64$

$3,83 \pm 3,15$

$1,74 \pm 2,59$

$3,56 \pm 3,01$

$1,55 \pm 2,49$

$1,70 \pm 2,56$

$5,00 \pm 2,75$
Test istatistiği

4,523

0,001

7,726

0,001

3,836

0,001

3,137

0,004

4,283

0,001

3,306

0,003
$1,87 \pm 2,67$

$1,82 \pm 2,75$

$1,73 \pm 2,31$

4,118

0,017

$2,753 \quad 0,038$

$3,63 \pm 3,05$

*t testine işaret etmektedir.

**Tek yönlü varyans analizine işaret etmektedir.

***Farklıığın kaynaklandığı grubu belirtmektedir.

\section{TARTIŞMA}

Çalışmamızda hasta bakıcıların \%42,3'ünün kas-iskelet sisteminde ağrı şikâyeti bulunduğu belirlenmiştir. Gül ve arkadaşlarının İstanbul'da çoğunluğu kadınlardan oluşan 217 hemşire ile Genişletilmiş Nordic Kas İskelet Anketi (GNKiSA) kullanılarak yaptığı çalışmada en az bir bölgesinde ağrı hisseden hemşirelerin oranı \%92,6 bulunmuştur (15). Janki ve arkadaşları tarafından 2017 'de cerrahlar üzerinde yapılmış bir çalışmada $\% 47,5$ oranında kas-iskelet sistemi sorunu yaşandığı bulunmuştur (16). Ayrıca Avrupa'da her dört çalışandan birinin sırt $(\% 24,7)$ ve kas ağrısından $(\% 22,8)$ yakındığı bilinmektedir (17). Bulgular kas-iskelet sistemine ilişkin ağrı şikâyetinin sık görülen bir sorun olduğunu göstermektedir. Bu durum çalışma şartlarının uygun ve çalışma ortamlarının ergonomik olmayışıyla ve uygun olmayan postürde çalışmayla ilişkilendirilebilir.
Araştırmamızda son 12 ay ve son 7 gün içerisinde hasta bakıcılarda en sık ağrıya neden olan üç vücut bölümü alt sırt, omuzlar ve üst sırttır. Akbaba ve Birinci'nin 136 hasta bakıcı ile yürüttükleri çalışmalarında hasta bakıcıların $\% 59$ 'unda bel ağrısı ve \%30,2'sinde hem boyun hem bel ağrısı görüldüğü belirlenmiştir (18). Gül ve arkadaşlarının İstanbul'da 217 hemşireyle yaptıkları çalışmalarında bel ağrısı; son bir yılda $\% 56,2$ ve son bir haftada $\% 32,7$ sıklıkta görülmüş olup en sık görülen ağrı olarak saptanmıştır (15). Şirzai ve arkadaşlarının İstanbul'da 125 sağlık çalışanıyla NKiSA kullanarak yaptığı çalışmada son 12 ayda ve son 7 günde en fazla ağrıya yol açan vücut bölümlerinin boyun ve sırt olduğu bulunmuştur (19). Soylu ve arkadaşlarının Sakarya ve Bilecik'te 83 diş hekimi ile GNKISA kullanarak yaptıkları çalışmada son 12 ay içinde kas-iskelet sistemi yakınmasına sahip olanların en fazla boyun $(\% 78,3)$, daha sonra bel $(\% 56,6)$ ve sırt bölgelerinde $(\% 55,4)$ yakınmalarının olduğu belirlenmiştir (9). Hem 
çalışmamızda hem de literatürde kas-iskelet sistemi ağrılarıyla ilişkili olarak öne çıkan bölgeler sırt, bel ve boyundur. Bu durum uygun olmayan çalışma postürüyle alakalı olabileceği gibi, çalışanların bu konulardaki eğitim ve dikkat eksiklikleriyle de alakalı olabilir.

Araştırmamızda hastabakıcıların VAS'a göre $\% 44,7$ 'sinin hafıf ağrısı, \%35'inin orta şiddette ağrısı ve \%20 ,4'ünün şiddetli ağrısı olduğu bulunmuştur. Fırıncı ve arkadaşlarının Malatya'da 250 hasta bakıcı ile yaptıkları çalışmada hastabakıcıların bel yakınmaları Oswestry skalası ile değerlendirilmiştir. Ağrı nedeniyle katılımcıların günlük hayatlarının \%72'sinin hafıf, \%22,4'ünün orta ve $\% 5,2$ 'sinin ciddi düzeylerde etkilendiği saptanmıştır (20). Subaşı ve arkadaşlarının Ankara'da 115 diş hekimi ile yürüttükleri çalışmada ağrısı olanların \%82,7'sinde ağrı şiddeti VAS'a göre 1-5 arasında bulunmuştur (21). Dilek ve arkadaşlarının İzmir'de 120 hekim ile yaptıkları çalışmada hekimlerin kas-iskelet yakınmalarına bağlı ağrı şiddetlerinin VAS'a göre hafif şiddette olduğu bulunmuştur (22). Çalışmamızın ve diğer çalışmaların bulguları sağlık alanında çalışan kişilerin kas-iskelet sistemi yakınmalarının büyük çoğunluğunun hafıf ve orta şiddette olduğunu göstermektedir. Çalışma ortamı, çalışma şartları ve gerektiğinde sağlık arama davranışı bu durumun olası nedenleri olarak gösterilebilir.

Son 12 ay içerisinde kas-iskelet sistemi ağrıları nedeniyle işe gidemediğini belirten hasta bakıcıların işten kalmasına sırasıyla alt sırt, boyun ve diz bölgelerinin sebep olduğu araştırmamız ile ortaya konmuştur. Gül ve arkadaşlarının 217 hemşireyle İstanbul'da yürüttükleri çalışmalarında kas-iskelet sistemi semptomu nedeniyle rapor alanların sırasıyla bel, sırt ve boyun ağrısı nedeniyle rapor aldıkları belirlenmiştir (15). Ayrıca Amerika, Kanada, Ingiltere, Finlandiya ve İsveç'te işe devamsızlıktan ve sakatlıklardan en fazla İ İH sorumlu tutulmaktadır (23, 24). Çalışmamızdaki ve literatürdeki bulgular ile IKIH'in sık görülen, işten kalmalara ve dolayısıyla ekonomik kayıplara yol açan durumlar olduğu ve halk sağlığı açısından önemli hastalıklar olduğu sonucuna varılabilir.

Araştırmamız sonucunda kadın olmak, tanı konulmuş bir kas-iskelet sistemi hastalığına sahip olmak, kadrolu çalışmak, son bir yıl içerisinde fiziksel tıp ve rehabilitasyon (FTR) ve ortopedi polikliniklerine başvurmak, son bir yıl içerisinde kas-iskelet sistemi rahatsızlığına bağlı istirahat almış olmak, sağlık sorunu nedeniyle iş değiştirmiş olmak ve üniversite mezunu olmak ağrı şiddetini arttıran değişkenler olarak belirlenmiştir. Literatürde kas-iskelet sistemi ağrısı ile ilgili genel risk faktörleri olarak; kadın cinsiyet, düşük gelirli olmak, eğitim düzeyi düşük olmak, kol gücüyle çalışmak, olumsuz çalışma koşullarına sahip olmak, alt sosyal sınıfa tabi olmak, stres ve mutsuzluk hissi, dört saatin üzerinde masa başı çalışmak, ilerleyen yaş, yüksek vücut kitle indeksi gibi pek çok değişkenden söz edilmektedir $(17,20,25)$. Araştırmamızda literatürle uyumlu risk faktörleri olduğu gibi uyumsuz risk faktörlerinin de bulunduğu görülmektedir. Bu durum çalışma gruplarının birbirlerinden farklı oluşuyla ve grupları meydana getiren kişilerin bireysel varyasyonlarıyla ilişkilendirilebilir.

\section{SONUÇ}

Hasta bakıcıların \%43,2'sinin kas-iskelet sisteminde ağrı şikayeti bulunduğu, son bir yıl içerisinde en sık alt sırt, omuz ve üst sırt ağrısı yaşandığı, \%79,7'sinin hafıf ve orta şiddette ağrısının olduğu, \%22,2'sinin kas-iskelet sistemi ilişkili kronik bir hastalık tanısı aldığı, \%73,5'inin ağrı kesici kullandığı, son bir yıl içerisinde en sık alt sırt, boyun ve diz ağrıları nedeniyle işten kaldıkları araştırmamız sonucunda elde ettiğimiz sonuçlardandır. Ayrıca kasiskelet sistemi ağrısı ve ağrı şiddeti ile kadın olmak, tanı konulmuş bir kas-iskelet sistemi hastalığına sahip olmak, kadrolu çalışmak, son bir yıl içerisinde FTR ve ortopedi polikliniklerine başvurmak, son bir yıl içerisinde kas-iskelet sistemi rahatsızlığına bağlı istirahat almış olmak, sağlık sorunu nedeniyle iş değiştirmiş olmak ve üniversite mezunu olmak arasında anlamlı bir ilişki saptanırken; medeni duruma, ağrı kesici kullanma durumuna ve çalıştıkları bölüme göre istatistiksel açıdan anlamlı fark saptanmamıştır.

Hasta bakıcılara kendi kas-iskelet sağlıklarını koruma konusunda farkındalık kazandırımasının yararlı olacağını düşünüyoruz. Çalışma ortamlarının ve çalışma şartlarının daha iyi hale getirilerek iş ile insan uyumunun sağlanması mevcut durumu daha olumlu hale getirecektir. Hasta bakıcılara uygun çalışma postürleri ile doğru taşıma ve kaldırma yöntemleri ile ilgili hem teorik hem de iş başında uygulamalı pratik eğitimlerin yapılması yararlı olabilir. Farklı sağlık kurumlarında benzer araştırmaların planlanması yeni risk faktörlerinin belirlenmesini sağlayabileceğinden önerilir.

Financial disclosures: All authors report no financial interests or potential conflicts of interest.

Conflict of Interest: The authors declare that they have no competing interest.

\section{REFERENCES}

1. Sayılan AA, Öztekin SD. Ameliyathane Hemşirelerinin Vücut Postürleri ve İlişkili Faktörler. Gümüşhane Üniversitesi Sağlık Bilimleri Dergisi 2018; 7(1): 23-7.

2. Arası D, Uskun E. Hemşirelerin Çalışma Ortamı Riskleri ve Yaşam Kalitesi ile İlişkisi. Tıp Araştırmaları Dergisi 2015; 13(2): 62-9.

3. Vural F, Sutsunbuloğlu E. Ergonomics: An Important Factor in the Operating Room. Journal of Perioperative Practice 2016; 26 (7-8): 175-9.

4. Smith DR, Wei N, Zhang YJ, Wang RS. Musculoskeletal Complaints and Psychosocial Risk Factors Among Physicians in Mainland China. Int J Indus Ergon 2006; 36(6): 599-603.

5. Yakut H, Yakut Y. Türkiye'deki Fizyoterapistlerde Kas İskelet Sistemi Yaralanmaları, Yorgunluk ve Mesleki Memnuniyetin Değerlendirilmesi. Fizyoterapi Rehabilitasyon 2011; 22(2): 74-80. 
6. Tunçay SU, Yeldan İ. Kas İskelet Sistemi Rahatsızlıklarıyla Fiziksel İnaktivite İlişkili midir? AĞRI 2013; 25(4): 147-55.

7. Buckle PW, Devereux JJ. The Nature of Work-Related Neck and Upper Limb Musculoskeletal Disorders. Appl Ergon 2002; 33(3): 207-17.

8. Harcombe H, McBride D, Derrett S, Gray A. Physical and Psychosocial Risk Factors for Musculoskeletal Disorders in New Zealand Nurses, Postal Workers and Office Workers. Inj Prev 2010; 16(2): 96-100.

9. Soylu M, Altındiş S. Diş Hekimlerinin Çalışma Şartlarının Mesleki Kas-ískelet Sistemi Hastalıklarına Etkisi. SDÜ Sağlık Bilimleri Enstitüsü Dergisi 2018; 9(1): 46-52.

10. Albersnagel FA. Velten and Music Mood Induction Procedures: A Comparision with Accessibility of Thought Associations. Behavioral Research and Theory 1988; 26(1): 79- 96 .

11. Aydın A, Araz A, Asan A. Görsel Analog Ölçeği ve Duygu Kafesi: Kültürümüze Uyarlama Çalışması. Türk Psikoloji Yazıları 2011; 14(27): 1-13.

12. Jones KR, Vojir CP, Hutt E, Fink R. Determining Mild, Moderate, and Severe Pain Equivalency Across Pain-Intensity Tools in Nursing Home Residents. J Rehabil Res Dev 2007; 44(2): 305-14.

13. Paul SM, Zelman DC, Smith M, Miaskowski C. Categorizing the Severity of Cancer Pain: Further Exploration of the Establishment of Cutpoints. Pain 2005; 113(1-2): 37-44.

14. Kuorinka I, Jonsson B, Kilbom A et al. Standardised Nordic Questionnaires for the Analysis of Musculoskeletal Symptoms. Appl Ergon 1987; 18(3): 233-7.

15. Gül A, Üstündağ $H$, Kahraman B, Purisa S. Hemşirelerde Kas İskelet Ağrılarının Değerlendirilmesi. HSP 2014; 1(1): 1-10.

16. Janki S, Mulder EEAP, ljzermans JNM, Tran TCK. Ergonomics in the Operating Room. Surg Endosc 2017; 31(6): 2457-66.

17. Türkkan A. İşe Bağlı Kas-İskelet Sistemi Hastalıkları ve
Sosyoekonomik Eşitsizlikler. Uludağ Üniversitesi Tıp Fakültesi Dergisi 2009; 35(2): 101-6.

18. Analay Akbaba Y, Birinci T. Hasta Bakıcılarda Bel-Boyun Ağrısının Değerlendirilmesi ve Ağrının Depresyon Üzerine Etkisinin İncelenmesi. ACU Sağlık Bil Derg 2019; 10(2): 23640.

19. Şirzai H, Doğu B, Erdem P, Yılmaz F, Kuran B. Hastane Çalışanlarında İşe Bağlı Kas İskelet Sistemi Hastalıkları: Üst Ekstremite Problemleri. Şişli Etfal Hastanesi Tıp Bülteni 2015; 49(2): 135-41.

20. Fırıncı B, Pehlivan E, Durmuş GN, Özer A. Hasta Bakıcılarda Bel Ağrısı ve Yaşam Kalitesinin Değerlendirilmesi: Turgut Özal Tıp Merkezi Örneği. Sakarya Tıp Dergisi 2018; 8(2): 292-302.

21. Subaşı N, Topbaşı N, Ülker G, Tahtacı T, Aydemir N, Çilingiroğlu N. Bir Ağız-Diş Sağlığı Merkezindeki Diş Hekimlerinde Kasİskelet Sistemi Ağrısı Sorununun Boyutu ve Sağlıkla İlgili Yaşam Kalitesine Etkisi. Hacettepe Diş Hekimliği Fakültesi Dergisi 2005; 29(3): 42-50.

22. Dilek B, Korkmaz F, Baş G, Deniz B, Yılmaz N, Doğan S ve ark. Bir Üniversite Hastanesinde Çalışan Hekimlerde Kas İskelet Sistemi Problemleri ve Yaşam Kalitesinin Değerlendirilmesi. DEÜ Tıp Fakültesi Dergisi 2016; 30(1): 25-30.

23. Punnet L, Wegman DH. Work-related Musculoskeletal Disorders: The Epidemiologic Evidence and the Debate. Journal of Electromyography and Kinesiology 2004; 14(1): 13-23.

24. CDC NIOSH. Worker Health Chartbook, 2004. https://www. cdc.gov/niosh/docs/2004-146/pdfs/2004-146.pdf (Erişim tarihi: 01.12.2019)

25. Cımbız A, Uzgören N, Aras Ö, Öztürk S, Elem E, Aksoy CC. Kas İskelet Sisteminde Ağrıya Ait Risk Faktörlerinin Lojistik Regresyon Analizi ile Belirlenmesi: Pilot Çalışma. Fizyoterapi Rehabilitasyon 2007; 18(1): 20-7. 